\title{
PENGARUH PEMBERIAN PISANG AMBON (Musa accuminata Colla) TERHADAP TEKANAN DARAH PENDERITA HIPERTENSI DI ATAS 45 TAHUN DI PUSKESMAS WAWOTOBI TAHUN 2017
}

\author{
Lymbran Tina* ${ }^{\star 凶}$, Risma Ulfianti”, Irma Yunawati*
}

\begin{abstract}
Abstrak
Hipertensi adalah salah satu penyakit pembuluh darah yang banyak menyerang lansia yang dikenal sebagai silent killer karena sering tidak menimbulkan gejala. Penelitian ini bertujuan untuk mengetahui dampak pemberian buah pisang ambon (Musa accuminata Colla) terhadap penurunan tekanan darah sistolik dan diastolik penderita hipertensi di wilayah kerja Puskesmas Wawotobi tahun 2017. Jenis penelitian ini adalah quasi eksperiment dengan desain pretest-posttest with control group. Jumlah subjek penelitian 30 penderita hipertensi yang memiliki tekanan darah sistolik $\geq 140 \mathrm{mmHg}$ dan diastolik $\geq 90 \mathrm{mmHg}$. Subjek dibagi menjadi 2 kelompok yaitu kelompok perlakuan dan kelompok kontrol dengan dosis $\pm 280 \mathrm{~g}$ buah pisang ambon selama 7 hari. Hasil uji statistik menunjukkan ada perbedaan nilai tekanan darah sistolik dan diastolik sebelum dan sesudah perlakuan pemberian buah pisang ambon selama 7 hari pada kelompok perlakuan $(p=0,000 ; a=0,05)$ dengan selisih penurunan tekanan darah sistolik sebesar $8,53 \mathrm{mmHg}$ dan tekanan darah diastolik sebesar $7,06 \mathrm{mmHg}$. Pada kelompok kontrol menunjukkan ada perbedaan nilai tekanan darah sistolik dan diastolik sebelum dan sesudah perlakuan $(p=0,000 ; a=0,05)$ dengan selisih penurunan tekanan darah sistolik sebesar $5,46 \mathrm{mmHg}$ dan tekanan darah diastolik 2,13 $\mathrm{mmHg}$. Jadi, dapat disimpulkan bahwa ada pengaruh pemberian buah pisang ambon terhadap penurunan tekanan darah sistolik dan diastolik penderita hipertensi. Konsumsi buah pisang khususnya pada lansia menjadi alternatif untuk pencegahan penyakit hipertensi.
\end{abstract}

Kata kunci: hipertensi, lansia, pisang ambon, tekanan darah.

\section{THE EFFECT OF AMBON BANANA (Musa Accuminata Colla) ON BLOOD HYPERTENSION PATIENTS ABOVE 45 YEARS IN WAWOTOBI PUBLIC HEALTH CENTER IN 2017}

\begin{abstract}
Hypertension is one of the blood vessel diseases that attack the elderly which known as the silent killer because it often does not cause symptoms. The purpose of this research was to describe the effect of ambon banana (Musa accuminata Colla) intake on decreasing systolic and diastolic blood pressure of hypertension patient in Wawotobi Public Health Center in 2017. This research was a quasi-experiment with pretestposttest control group design. There were 30 patients with hypertension who have systolic blood pressure $\geq 140 \mathrm{mmHg}$ and diastolic $\geq 90 \mathrm{mmHg}$ as research subjects. The subjects were divided into 2 groups: treatment group and control group with the dosage of intake approximately $280 \mathrm{~g}$ of bananas for 7 days. The statistical test showed that there was a difference of systolic and diastolic blood pressure values before and after the intake of bananas for 7 days in the treatment group $(p=0.000 ; a=0.05)$ with decreasing difference of systolic blood pressure was $8.53 \mathrm{mmHg}$ and diastolic blood pressure was $7.06 \mathrm{mmHg}$. While in the control group showed that there was a difference of systolic and diastolic blood pressure values before and after treatment in control group $(p=0.000 ; a=0.05)$ with decreasing difference of systolic blood pressure of 5.46 $\mathrm{mmHg}$ and diastolic blood pressure of $2.13 \mathrm{mmHg}$. So, it can be concluded that ambon banana intake can decrease systolic and diastolic blood pressure on hypertension patients. consumption of bananas, especially in elderly can be an alternative for the prevention of hypertension disease.
\end{abstract}

Keywords: ambon bananas, blood pressure, elderly, hypertension.

* Departemen Epidemiologi, Fakultas Kesehatan Masyarakat, Universitas Halu Oleo

${ }^{* *}$ Departemen Gizi, Fakultas Kesehatan Masyarakat, Universitas Halu Oleo

E-mail: lymbranizzah@gmail.com 


\section{Pendahuluan}

Transisi epidemiologi menyebabkan peningkatan prevalensi dari penyakit menular menjadi penyakit tidak menular (non-communicable disease) termasuk hipertensi, baik di dunia maupun di Indonesia. Transisi epidemiologi disebabkan oleh perubahan struktur penduduk, sosial ekonomi dan lingkungan. Gaya hidup yang tidak sehat, seperti merokok, kurang aktifitas fisik, makanan tinggi lemak dan kalori, serta konsumsi alkohol diduga merupakan faktor risiko penyakit tidak menular (PTM) . ${ }^{1}$

Hipertensi merupakan salah satu penyakit pembuluh darah yang dikenal sebagai silent killer karena sering tidak menimbulkan gejala. Sebagian besar penderita hipertensi di Indonesia tidak terdeteksi, sementara mereka yang terdeteksi umumnya tidak menyadari kondisi penyakitnya dan hanya sebagian kecil yang berobat secara teratur. Secara umum, hipertensi merupakan suatu keadaan tanpa gejala. Adanya tekanan darah yang tinggi di dalam arteri menyebabkan meningkatnya risiko terhadap penyakit-penyakit yang berhubungan dengan kardiovaskuler seperti stroke, gagal ginjal, serangan jantung, dan kerusakan ginjal. ${ }^{2}$

Data dari World Health Organization (WHO) tahun 2012 menyebutkan bahwa prevalensi hipertensi mengalami penurunan secara global dari 32\% pada tahun 1980 menjadi $27 \%$ di tahun 2008, tetapi tahun 2012 sampai 2015 mengalami peningkatan mencapai $31,7 \%$. Prevalensi hipertensi diperkirakan akan terus meningkat dan diprediksi pada tahun 2025 sebanyak 29\% orang dewasa di dunia menderita hipertensi. Di sisi lain, terjadi peningkatan di negara berkembang seperti di wilayah Afrika yang menempati posisi pertama dengan jumlah penduduk penderita hipertensi sebesar $46 \%$. Di Asia Tenggara penduduk yang mengalami hipertensi sebesar 36\% dan Amerika Serikat menempati urutan paling bawah dengan penduduk yang mengalami hipertensi sebesar $35 \%$. ${ }^{3}$

Di Indonesia, prevalensi hipertensi menunjukkan peningkatan dari tahun ke tahun. Menurut Riset Kesehatan Dasar (Riskesdas) tahun 2013 bahwa proporsi angka kematian akibat penyakit tidak menular meningkat dari $41,7 \%$ menjadi $60 \%$, dan terjadi peningkatan prevalensi hipertensi dari $7,6 \%$ menjadi 9,5\% tahun 2013. Berdasarkan Survei Kesehatan Rumah Tangga (SKRT) Kementerian Kesehatan RI 2015 menyebutkan bahwa sekitar 26-31\% dari populasi masyarakat Indonesia diberbagai provinsi menderita hipertensi.

Data Surveilans Terpadu Penyakit Berbasis Puskesmas (STP) dari Dinas Kesehatan Provinsi Sulawesi Tenggara Tahun 2013 sampai 2016, menunjukkan bahwa prevalensi hipertensi mengalami peningkatan yang signifikan dari tahun ke tahun. Tahun 2014 prevalensi hipertensi sebanyak 9,7\%. Tahun 2015 hipertensi menjadi $14,1 \%$ dan pada tahun 2016 meningkat sebesar $17,2 \%{ }^{4}$

Berdasarkan data dari Dinas Kesehatan Kabupaten Konawe dari tahun 2013 sampai 2016, hipertensi termasuk ke dalam 20 besar penyakit dan angka kesakitan puskesmas di Kabupaten Konawe. Pada tahun 2013 prevalensi hipertensi sebanyak 9,3\% kasus dan tahun 2014 jumlah kasus menjadi $14 \%$. Hipertensi semakin meningkat menjadi $16 \%$ pada tahun 2015 dan pada bulan Januari sampai Juni 2016 sudah mencapai 20\%. ${ }^{5}$

Data hipertensi kelompok umur di atas 45 tahun yang diperoleh dari Puskesmas Wawotobi dari tahun 2013 sampai 2016 termasuk salah satu dari lima besar puskesmas dengan kunjungan hipertensi terbanyak di Kabupaten Konawe. Selama tiga tahun terakhir, hipertensi berada pada urutan ke-lima dari sepuluh besar penyakit sehingga masih menjadi masalah kesehatan 
di Puskesmas Wawotobi. Pada tahun 2013, prevalensi hipertensi sebanyak $14,0 \%$. Tahun 2014 mengalami penurunan menjadi $12,5 \%$ dan meningkat kembali pada tahun 2015 menjadi 13,5\%, sedangkan pada tahun 2016 dari bulan Januari sampai Juni sudah mencapai $14,5 \%{ }^{6}$

Pengobatan hipertensi selain menggunakan obat-obatan kimiawi, dapat juga menggunakan pengobatan herbal. Saat ini, pengobatan herbal lebih diminati oleh masyarakat karena praktis, mudah didapat serta efek sampingnya yang sedikit. Salah satu pengobatan herbal untuk hipertensi yaitu dengan mengkonsumsi buah-buahan yang mengandung kalium tinggi seperti pisang. Pisang merupakan buah yang tinggi kalium yang dapat berfungsi untuk vasodilitasi, mengatur denyut jantung serta mengatur keseimbangan cairan dalam tubuh sehingga dapat membantu menurunkan tekanan darah. ${ }^{7}$

Berdasarkan latar belakang di atas, maka dilakukan penelitian tentang pengaruh pemberian pisang ambon (Musa accuminata Colla) pada penderita hipertensi umur di atas 45 tahun di wilayah kerja Puskesmas Wawotobi tahun 2017.

\section{Bahan dan Metode}

Tujuan dari penelitian ini adalah untuk mengetahui efek dari pemberian buah pisang ambon kepada penderita hipertensi. Metodologi penelitian yang digunakan adalah penelitian eksperimen semu (quasi eksperiment) dengan rancangan penelitian menggunakan pre-test post-test with control group design. Pada kelompok perlakuan diberikan intervensi berupa pemberian pisang ambon dan edukasi kesehatan dengan media leafleat dan pada kelompok kontrol hanya diberikan edukasi kesehatan menggunakan leafleat.

Populasi dalam penelitian ini adalah seluruh penderita hipertensi pada kelompok umur di atas 45 tahun yang tercatat dalam buku registrasi pasien di Puskesmas Wawotobi Kabupaten Konawe pada bulan Januari sampai Juni pada tahun 2016 yaitu sebanyak 145 orang. Cara penentuan jumlah sampel menggunakan rumus besar sampel untuk penelitian analisis numerik berpasangan, sehingga didapatkan total sampel sebanyak 30 orang.

Proses pengambilan sampel dilakukan berdasarkan beberapa kriteria yaitu, (a). Responden merupakan warga yang berdomisili di Wawotobi, (b). Usia responden di atas 45 tahun, (c). Memiliki tekanan darah $\geq 140 \mathrm{mmHg}$ (sistolik) dan $\geq 90 \mathrm{mmHg}$ (diastolik), (d). Tidak sedang mengkonsumsi obat penurun tekanan darah, (e). Bersedia tanpa ada paksaan mengikuti proses riset ini. Metode penarikan sampel dengan teknik purposive sampling (pertimbangan tertentu peneliti secara logis).

Instrumen penelitian yang digunakan dalam penelitian ini yaitu, (1). Buah pisang ambon ditimbang menggunakan timbangan makanan sebelum diberikan pada kelompok perlakuan dengan berat/buah $\pm 140 \mathrm{~g}$ dengan dosis 2 kali sehari diberikan selama 7 hari, (2). Leaflet yang berisi gambar serta penjelasan penyakit hipertensi, (3). Sphymomanometeraneroid dan stetoscope yang bersifat manual untuk mengetahui tekanan darah, (4). Timbangan badan digunakan untuk mengukur berat badan, sedangkan untuk mengukur tinggi badan menggunakan mikrotoice, (5). Kuisioner untuk mengumpulkan identitas/karakteristik responden meliputi umur, jenis kelamin, pendidikan, pekerjaan, alamat, tekanan darah, berat badan dan tinggi badan, (6). Alat dokumentasi berupa kamera atau handphone berkamera, (7). Alat tulis dan komputer untuk mengolah data yang diperoleh serta yang digunakan dalam penyusunan laporan penelitian.

Jenis data yang digunakan dalam penelitian ini yaitu data primer yang 
diperoleh langsung dari subjek penelitian dalam bentuk daftar pertanyaan recall $2 \times 24$ jam dan edukasi kesehatan (lefleat) kepada responden dan data sekunder yang bersumber dari pemerintah propinsi Sulawesi Tenggara dan data dari Puskesmas Wawotobi Tahun 2016.

\section{Hasil}

Penelitian ini mendapatkan rata-rata tekanan darah sistolik responden pada kelompok perlakuan sebelum intervensi adalah 158,93 $\mathrm{mmHg}$ dengan standar deviasi 5,03 dan sesudah intervensi adalah $150,40 \mathrm{mmHg}$ dengan standar deviasi 3,79. Pada kelompok kontrol diketahui rata-rata tekanan darah sistolik responden sebelum adalah $159,73 \mathrm{mmHg}$ dengan standar deviasi 4,55 dan sesudah intervensi adalah 154,27 dengan standar deviasi 4,07 (Tabel 1). Lalu, untuk rata-rata tekanan darah diastoloik responden pada kelompok perlakuan sebelum intervensi adalah 99,47 $\mathrm{mmHg}$ dengan standar deviasi 2,92, dan sesudah intervensi adalah $92,47 \mathrm{mmHg}$ dengan standar deviasi 1,12. Pada kelompok kontrol, rata-rata tekanan darah sistolik responden sebelum intervensi adalah 97,20 $\mathrm{mmHg}$ dengan standar deviasi 1,90 dan sesudah intervensi adalah 95,07 dengan standar deviasi 1,04 (Tabel 2).

Pada Tabel 3 dapat diketahui rata-rata penurunan tekanan darah sistolik pada kelompok perlakuan adalah 186,67 $\mathrm{mmHg}$ dengan nilai minimum 83,3 dan nilai maksimum 93 dengan standar deviasi 8,99. Sementara itu, rata-rata penurunan tekanan darah sistolik pada kelompok kontrol sekitar $98,00 \mathrm{mmHg}$ dengan nilai minimum 83,4 dan nilai maksimum 94 dengan standar deviasi 4,14. Kemudian pada Tabel 4 ditampilkan rata-rata penurunan tekanan darah sistolik pada kelompok perlakuan sebesar $104,67 \mathrm{mmHg}$ dengan nilai minimum 3,6 dan nilai maksimum 9,0 dengan standar deviasi 10,60 . Sementara rata-rata penurunan tekanan darah sistolik pada kelompok kontrol sekitar 102,00 dengan nilai minimum 3,7 dan nilai maksimum 9,1 dengan standar deviasi 5,60.

Tabel 1. Hasil pengukuran tekanan darah sistolik sebelum dan sesudah intervensi pada kelompok perlakuan dan kelompok kontrol di Puskesmas Wawotobi tahun 2017.

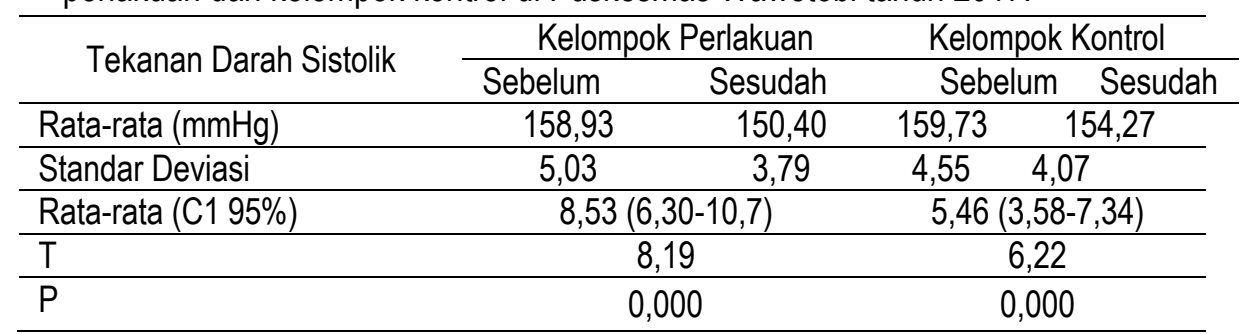

Sumber: Data primer, September 2017

Tabel 2. Hasil pengukuran nilai tekanan darah diastolik sebelum dan sesudah intervensi pada kelompok perlakuan dan kelompok kontrol di Puskesmas Wawotobi tahun 2017.

\begin{tabular}{|c|c|c|c|c|}
\hline \multirow{2}{*}{ Tekanan Darah Diastolik } & \multicolumn{2}{|c|}{ Kelompok Perlakuan } & \multicolumn{2}{|c|}{ Kelompok Kontrol } \\
\hline & Sebelum & Sesudah & Sebelum & Sesudah \\
\hline Rata-rata $(\mathrm{mmHg})$ & 99,47 & 92,47 & 97,20 & 95,07 \\
\hline Standar deviasi & 2,92 & 1,12 & 1,90 & 1,04 \\
\hline Rata-rata (C1 95\%) & \multicolumn{2}{|c|}{$7,06(9,00-5,13)$} & \multicolumn{2}{|c|}{$2,13(2,96-1,30)$} \\
\hline$T_{1}$ & \multicolumn{2}{|c|}{7,83} & \multicolumn{2}{|c|}{5,48} \\
\hline$P$ & \multicolumn{2}{|c|}{0,000} & \multicolumn{2}{|c|}{0,000} \\
\hline
\end{tabular}

Sumber: Data primer, September 2017 
Tabel 3. Hasil pengukuran selisih nilai tekanan darah sistolik sebelum dan sesudah intervensi pada kelompok perlakuan dan kelompok kontrol di Puskesmas Wawotobi tahun 2017.

\begin{tabular}{lcc}
\hline Selisih Nilai Tekanan Darah Sistolik & Kelompok Perlakuan & Kelompok Kontrol \\
\hline Rata-rata (mmHg) & 186,67 & 98,00 \\
\hline Standar deviasi & 8,99 & 4,14 \\
\hline Minimum & 83,4 & 83,3 \\
\hline Maksimum & 93 & 94
\end{tabular}

Sumber: Data primer, September 2017

Tabel 4. Hasil pengukuran selisih nilai tekanan darah diastolik sebelum dan sesudah intervensi pada kelompok perlakuan dan kelompok kontrol di Puskesmas Wawotobi tahun 2017.

\begin{tabular}{lcc}
\hline Selisih Nilai Tekanan Darah Diastolik & Kelompok Perlakuan & Kelompok Kontrol \\
\hline Rata-rata (mmHg) & 104,67 & 102,00 \\
\hline Standar deviasi & 10,60 & 5,60 \\
\hline Minimum & 3,6 & 3,7 \\
\hline Maksimum & 9,0 & 9,1 \\
\hline
\end{tabular}

Sumber: Data primer, September 2017

\section{Pembahasan}

Penelitian ini menunjukkan bahwa lansia di Puskesmas Wawotobi yang berusia di atas 45 tahun merupakan penderita hipertensi dengan kategori tekanan darah sistolik $\geq 140 \mathrm{mmHg}$ dan tekanan darah diastolik $\geq 90$. Tekanan darah adalah tekanan yang ditimbulkan pada dinding arteri dengan tekanan puncak terjadi pada saat ventrikel berkontraksi atau disebut tekanan sistolik, dan tekanan darah terendah atau tekanan diastolik yang terjadi pada saat jantung beristirahat. Tekanan darah biasanya digambarkan sebagai rasio tekanan sistolik terhadap tekanan diastolik, dengan nilai dewasa normalnya berkisar dari 100/60 sampai 140/90. Rata-rata tekanan darah normal biasanya 120/80. ${ }^{9}$

Buah pisang yang mengandung tinggi kalium diketahui dapat menyebabkan penurunan tekanan darah. Dalam sebuah riset telah dibuktikan bahwa asupan kalium yang terdapat pada pisang ambon dapat secara efektif menurunkan tekanan darah pada seorang yang menderita hipertensi yakni $4,4 \mathrm{mmHg}$ (sistolik) dan $2,5 \mathrm{mmHg}$ (diastolik). Namun berbeda pada golongan dengan tekanan darah normal yakni 1,8 $\mathrm{mmHg}$ (sistolik) dan $1,0 \mathrm{mmHg}$ (diastolik). ${ }^{10}$

Pada penelitian ini, lansia penderita hipertensi yang mengkonsumsi 2 buah pisang ambon dalam sehari selama seminggu dapat menurunkan tekanan darah sistolik maupun diastolik. Hal ini sesuai dengan riset di Amerika Serikat (2003) yang menyebutkan bahwa penderita hipertensi yang berusia 35-50 tahun yang mengkonsumsi 2 buah pisang setiap hari mengalami penurunan tekanan darah sampai 10\% dalam 1 minggu. ${ }^{11}$ Penelitian yang dilakukan oleh Tangkilisan (2013) tentang pengaruh terapi diet pisang ambon (Musa paradisiaca var. sapientum Linn) terhadap penurunan tekanan darah pada klien hipertensi mengatakan bahwa diet terapi dan mengkonsumsi buah pisang ambon dapat menurunkan tekanan darah sistolik maupun diastolik. ${ }^{12}$

Kalium dapat menurunkan tekanan darah sistolik dan diastolik, hal ini didukung oleh penelitian Donald dan Alesandro (2008) bahwa pemberian suplemen potassium selama 6 minggu didapatkan nilai tekanan darah sistolik rata-rata setelah 6 minggu pemberian sebesar $7,60 \mathrm{mmHg}$ dan diastolik 
sebesar 6,46 mmHg. Kandungan kalium dapat memicu kerja otot dan simpul saraf. Di dalam tubuh kalium berfungsi dalam menjaga keseimbangan cairan-elektrolit dan keseimbangan asam-basa. Selain itu, bersama dengan kalsium dan natrium, kalium akan berperan dalam tranmisi saraf, pengaturan enzim dan kontraksi otot. ${ }^{13}$

Konsumsi 2 buah pisang ambon dalam sehari dengan dosis \pm 280 gram perhari untuk mencukupi asupan kalium perhari yang dapat menurunkan tekanan darah sistolik maupun diastolik sehingga dapat mencegah terjadinya hipertensi serta dapat memperpanjang harapan hidup. Selain itu, buah pisang ambon sangat baik dikonsumsi sebagai alternatif pengganti obat antihipertensi karena cara kerjanya mirip dengan cara kerja obat antihipertensi dan bisa dimanfaatkan untuk terapi nonfarmakologis yang berguna bukan hanya sebagai pengobatan tapi juga bisa konsumsi untuk membantu sistem pencernaan seperti sembelit. ${ }^{14}$

\section{Kesimpulan}

Ada perbedaan penurunan tekanan darah sistolik dan diastolik antara kelompok perlakuan dan kelompok kontrol sebelum dan sesudah perlakuan sehingga dapat dikatakan bahwa pemberian buah pisang ambon berpengaruh terhadap penurunan tekanan darah sistolik dan diastolik responden pada kelompok perlakuan dan kelompok kontrol.

\section{Saran}

1. Bagi pemerintah khususnya pihak pusat pelayanan masyarakat hendaknya dapat membuat program-program kesehatan khususnya untuk lansia penderita hipertensi dengan menggunakan media/alat bantu untuk memberikan pengetahuan agar dapat meningkatkan kewaspadaan masyarakat akan bahaya penyakit tidak menular termasuk penyakit hipertensi agar lebih mengontrol tekanan darah secara rutin.

2. Konsumsi natrium, IMT, serta stres pada lansia penderita hipertensi perlu dikontrol karena menjadi salah satu pemicu terjadinya penyakit hipertensi yang paling dominan.

3. Pengembangan penelitian diperlukan kedepannya agar dapat mengontrol berbagai faktor yang dapat menimbulkan bias penelitian, misalnya asupan natrium dalam kasus hipertensi.

\section{Daftar Pustaka}

1. Rahajeng $\mathrm{K}$, Tuminah S. Prevalensi Hipertensi dan Determinannya di Indonesia. Jurnal Maj Kedokt Indon. 2010; 59(12).

2. Sutanto. Cekal (Cegah dan Tangkal) Penyakit Modern Hipertensi, Stroke, Jantung, Kolestrol, dan Diabetes. Yogyakarta: C.V Andi Offset. 2010.

3. (WHO) World Health Organization. A Global Brief on Hypertension-Silent Killer, Global Public Crisis. Geneva: WHO Press. 2012.

4. Riskesdas. Riset Kesehatan Dasar Tahun 2013. Badan Penelitian dan Pengembangan Kesehatan Kementerian Kesehatan Rl. Jakarta. 2013.

5. Kepmenkes. Laporan Riset Kesehatan Dasar Tahun 2013. (Online). 2013. (http://www.litbang.Depkes.go.id/sites/d ownload/buku laporan riskesdas2013/La poranriskesdas 2013.pdf).

6. Widjaja $F$, Santoso LA, Barus NRV, Pradana GA, Estetika C. Prehypertension and Hypertension among Young Indonesian Adults at $A$ Primary Health Care in A Rural Area. Medical Journal of Indonesia. 2013; 22(1):39-45. 
7. Batin. Pengaruh Pemberian Jus Mentimun, Papaya dan Semangka Terhadap Tekanan Darah Sistolik dan Diastolik Penderita Hipertensi di Wilayah Kerja Puskesmas Liya Kabupaten Wakatobi Tahun 2017. Kendari. Fakultas Kesehatan Masyarakat, Universitas Halu Oleo. 2017.

8. Octivia R, Gunawan D, Puspasari G. Pengaruh Kombinasi Pisang Ambon (Musa paradisiaca, Linn) dan Stroberi (Fragaria vesca) Terhadap Penurunan Tekanan Darah Normal pada Perempuan Dewasa. Skripsi. Bandung: Fakultas Kedokteran.Universitas Kristen Maranatha. 2014.

9. Smeltzer CS dan Bare GB. Buku Ajar Keperawatan Medikal Bedah. Edisi ke8. Jakarta: EGC. 2011.

10. Tryastuti D. Pengaruh Konsumsi Pisang Ambon (Musa paradisiaca S) Terhadap Tekanan Darah Lansia Penderita Hipertensi Sedang di Panti Sosial Tresna Werdhasabai Nan Aluih Sicincin. Skripsi. Padang: Program Studi
Keperawatan Fakultas Kedokteran Universitas Andalas. 2012.

11. Tangkilisan LR, Kalangi S, Masi G. Pengaruh Terapi Diet Pisang Ambon (Musa paradisiaca Var. Sapientum Linn) Terhadap Penurunan Tekanan Darah pada Klien Hipertensi di kota Bitung. Jurnal Keperawatan. 2013; 1(1):1-6.

12. Irawan AM. Cairan Tubuh, Elektrolit dan Mineral. (Online). 2007. Polton Sports Science and Performance lab. https://www.scribd.com/doc/258692113/e lektrolit-tubuh-pdf.

13. Naismith DJ and Braschi A. The Effect of Low-Dose Potassium Suplementation on Blood Pressure in Apparently Healthy Volunteers. British Journal of Nutrition. 2003; 90:53-60.

14. Sugiharto $A$. Faktor-faktor Risiko Hipertensi Grade II pada Masyarakat; Studi kasus di Kabupaten Karanganyar. Tesis. Semarang: Program Pasca Sarjana Universitas Diponegoro. 2007. 